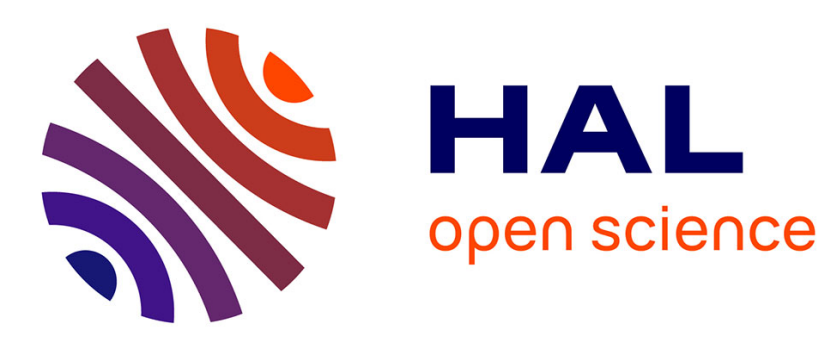

\title{
Displacement-velocity correction schemes for incompressible fluid-structure interaction
}

Miguel Angel Fernández, Jimmy Mullaert

\section{To cite this version:}

Miguel Angel Fernández, Jimmy Mullaert. Displacement-velocity correction schemes for incompressible fluid-structure interaction. Comptes Rendus. Mathématique, 2011, 349 (17-18), pp.1011-1015. 10.1016/j.crma.2011.08.004 . inria-00583126v2

\section{HAL Id: inria-00583126 https://hal.inria.fr/inria-00583126v2}

Submitted on 14 Sep 2011

HAL is a multi-disciplinary open access archive for the deposit and dissemination of scientific research documents, whether they are published or not. The documents may come from teaching and research institutions in France or abroad, or from public or private research centers.
L'archive ouverte pluridisciplinaire HAL, est destinée au dépôt et à la diffusion de documents scientifiques de niveau recherche, publiés ou non, émanant des établissements d'enseignement et de recherche français ou étrangers, des laboratoires publics ou privés. 


\title{
Displacement-velocity correction schemes for incompressible fluid-structure interaction
}

\author{
Miguel A. Fernández a and Jimmy Mullaert ${ }^{\mathrm{a}}$

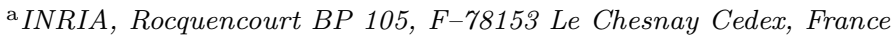 \\ Received $* * * * * ;$ accepted after revision +++++ \\ Presented by ?????
}

\begin{abstract}
We propose a new class of time-marching schemes for the explicit coupling of an incompressible fluid and an elastic solid (not necessarily thin). We state a general energy-based stability result and illustrate the accuracy of the different variants in a numerical benchmark. To cite this article: A. Name1, A. Name2, C. R. Acad. Sci. Paris, Ser. I 340 (2005).

\section{Résumé}

Schémas de correction de déplacement-vitesse en interaction fluide incompressible/structure. Nous proposons une nouvelle classe de schémas de couplage explicite pour l'interaction entre un fluide incompressible et une structure élastique dans le cas où la structure n'est pas nécessairement mince. On énonce un résultat de stabilité général pour ces nouveaux schémas et on analyse numériquement leur précision. Pour citer cet article : A. Name1, A. Name2, C. R. Acad. Sci. Paris, Ser. I 340 (2005).
\end{abstract}

\section{Version française abrégée}

La stabilité des approximations numériques de problèmes d'interaction fluide-structure, comportant un fluide incompressible et une structure élastique, est très sensible au traitement discret des conditions de couplage à l'interface (voir [1], p.e., pour une revue). C'est seulement récemment que des schémas de couplage explicite stables ont été proposés dans la littérature [2,3,4]. Dans le cadre d'un couplage avec une structure mince, les schémas introduits dans [3,4] combinent une méthode à pas fractionnaire dans le solide avec un traitement implicite du couplage entre les efforts du fluide et les contributions hydrodynamiques du solide (masse et ammortissement). Ces méthodes sont de type correction de déplacement (non-incrémentale [3] ou incrémentale [4]).

Email addresses: miguel.fernandez@inria.fr (Miguel A. Fernández), jimmy.mullaert@inria.fr (Jimmy Mullaert). 
Dans cette note, nous proposons une généralisation (la première, à notre connaissance) des schémas de couplage explicite introduits dans $[3,4]$ dans le cas d'un solide épais. On considère ainsi le problème couplé (1)-(2), qui modélise l'interaction entre un fluide linéaire newtonien incompressible et une structure élastique linéaire (avec ou sans amortissement), dont la formulation variationnelle est donnée par (3). Le détail des schémas de couplage explicite proposés est présenté dans l'Algorithme 1. L'idée principale regroupe les trois ingrédients suivants. Le premier consiste à traiter explicitement l'amortissement du solide (si pris en compte dans (1)) par rapport au fluide. Le deuxième repose sur le calcul découplé de la vitesse intermédiaire du solide (interface et contributions internes, première et deuxième étapes de l'Algorithme 1) par condensation de la de masse dans la structure. Enfin, le dernier consiste à extrapoler à la fois le déplacement et la vitesse du solide (schémas incrémentaux).

Nous présentons également un résultat général de stabilité qui traite à la fois les variantes increméntale et non-incrémentales (voir la Proposition 4.1). En particulier, ce résultat montre que le schéma nonincrémental et le schéma incrémantal avec extrapolation de premier ordre sont inconditionnellement stables. La variante incrémentale avec extrapolation d'ordre deux est stable sous une condition de type CFL (hyperbolique/parabolique). Finalment, la précision supérieure des schémas incrémentaux est illustrée par des expériences numériques (voir la Figure 1).

\section{Introduction}

The stability of the numerical approximations of fluid-structure interaction problems involving a viscous incompressible fluid and an elastic structure is very sensitive to the way the interface coupling conditions (kinematic and kinetic continuity) are enforced at the discrete level (see, e.g., [1] for a review). Stable explicit coupling schemes (i.e., that only involve one, or a few, fluid and solid resolutions per timestep) have only recently been proposed in the literature [2,3,4]. In [2], stability is achieved through an appropriate Robin-Robin treatment of the interface coupling and the addition of a weakly consistent interface compressibility term. Yet, defect-correction iterations are required to guarantee accuracy. In the case of thin structures (e.g., string, plate, membrane or shell models), the procedures reported in $[3,4]$ combine the splitting of the solid time-marching with an implicit coupling of the interface fluid stress and the hydrodynamic solid contributions (inertia and damping), fully embedded into the fluid sub-problem through a generalized Robin boundary condition. These coupling procedures are a class of displacement-correction schemes. The non-incremental variant [3] ignores the displacement in the first step and, hence, may lack accuracy. The incremental schemes [4], on the contrary, achieve optimal accuracy by extrapolating the displacement in the first step (corrected accordingly in the second).

In this note, we propose a generalization (the first, to the best of our knowledge) of the explicit coupling schemes reported in [3,4] to the case of thick structures: two- and three-dimensional (possibly damped) linear elasticity. These new schemes are based on the following three main ideas. The first consists of treating explicitly (whenever present) the solid damping with respect to the fluid. The second relies on the uncoupled computation of the intermediate solid velocity (interface and internal contributions) via a mass-lumping approximation of the structure inertia. At last, the third consists of extrapolating both the displacement and the velocity (incremental schemes). We present a general stability result which covers both the non-incremental and the incremental variants. The analysis shows, in particular, that the non-incremental and the first-order extrapolated incremental schemes are unconditionally stable. The incremental variant with second-order extrapolation is stable under a CFL-like (hyperbolic/parabolic) condition. The superior accuracy of the incremental variants is illustrated in a numerical benchmark. 


\section{A linear model problem}

We consider a low Reynolds regime and assume that the interface undergoes infinitesimal displacements. The fluid is described by the Stokes equations, in a fixed domain $\Omega^{\mathrm{f}} \subset \mathbb{R}^{d}(d=2,3)$, and the structure by the linear (possibly damped) elasticity equations, in the solid domain $\Omega^{\mathrm{s}} \subset \mathbb{R}^{d}$. We denote by $\Sigma \stackrel{\text { def }}{=}$ $\partial \Omega^{\mathrm{s}} \cap \partial \Omega^{\mathrm{f}}$ the fluid-structure interface and $\partial \Omega^{\mathrm{f}}=\Gamma \cup \Sigma$ and $\partial \Omega^{\mathrm{s}}=\Gamma^{\mathrm{d}} \cup \Gamma^{\mathrm{n}} \cup \Sigma$ are given partitions of the external boundary. Our linear coupled problem reads as follows: Find the fluid velocity $\boldsymbol{u}: \Omega^{\mathrm{f}} \times \mathbb{R}^{+} \rightarrow \mathbb{R}^{d}$, the fluid pressure $p: \Omega^{\mathrm{f}} \times \mathbb{R}^{+} \rightarrow \mathbb{R}$, and the structure displacement $\boldsymbol{d}: \Omega^{\mathrm{s}} \times \mathbb{R}^{+} \rightarrow \mathbb{R}^{d}$ such that

$$
\left\{\begin{array} { r l c } 
{ \rho ^ { \mathrm { f } } \partial _ { t } \boldsymbol { u } - \operatorname { d i v } \boldsymbol { \sigma } ^ { \mathrm { f } } ( \boldsymbol { u } , p ) = \mathbf { 0 } } & { \text { in } } & { \Omega ^ { \mathrm { f } } , } \\
{ \operatorname { d i v } \boldsymbol { u } = 0 } & { \text { in } } & { \Omega ^ { \mathrm { f } } , } \\
{ \boldsymbol { \sigma } ^ { \mathrm { f } } ( \boldsymbol { u } , p ) \boldsymbol { n } ^ { \mathrm { f } } = - p _ { \Gamma } \boldsymbol { n } ^ { \mathrm { f } } } & { \text { on } \quad \Gamma , }
\end{array} \quad \left\{\begin{array}{rcc}
\rho^{\mathrm{s}} \partial_{t} \dot{\boldsymbol{d}}+c_{1} \dot{\boldsymbol{d}}-\operatorname{div} \boldsymbol{\sigma}^{\mathrm{s}}(\boldsymbol{d}, \dot{\boldsymbol{d}})+c_{0} \boldsymbol{d}=\mathbf{0} & \text { in } & \Omega^{\mathrm{s}}, \\
\dot{\boldsymbol{d}}=\partial_{t} \boldsymbol{d} & \text { in } & \Omega^{\mathrm{s}}, \\
\boldsymbol{d}=\mathbf{0}, \beta \dot{\boldsymbol{d}}=\mathbf{0} & \text { on } & \Gamma^{\mathrm{d}}, \\
\boldsymbol{\sigma}^{\mathrm{s}}(\boldsymbol{d}, \dot{\boldsymbol{d}}) \boldsymbol{n}^{\mathrm{s}}=\mathbf{0} & \text { on } & \Gamma^{\mathrm{n}},
\end{array}\right.\right.
$$

satisfying the interface coupling conditions

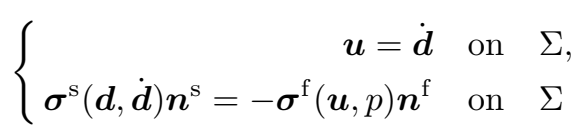

and the initial conditions $\boldsymbol{u}(0)=\boldsymbol{u}_{0}, \boldsymbol{d}(0)=\boldsymbol{d}_{0}$ and $\dot{\boldsymbol{d}}(0)=\boldsymbol{v}_{0}$. Here, $\rho^{\mathrm{f}}, \rho^{\mathrm{s}}>0$ stand for the fluid and solid densities, $\boldsymbol{\sigma}^{\mathrm{f}}(\boldsymbol{u}, p) \stackrel{\text { def }}{=}-p \boldsymbol{I}+2 \mu \boldsymbol{\epsilon}(\boldsymbol{u})$ for the fluid stress tensor, $\mu>0$ for the fluid dynamic viscosity, $\boldsymbol{\epsilon}(\boldsymbol{u}) \stackrel{\text { def }}{=}\left(\boldsymbol{\nabla} \boldsymbol{u}+\boldsymbol{\nabla} \boldsymbol{u}^{\mathrm{T}}\right) / 2, p_{\Gamma}$ for a given pressure on $\Gamma$ and $\boldsymbol{n}^{\mathrm{f}}, \boldsymbol{n}^{\mathrm{s}}$ for the exterior unit normal vectors. The solid stress tensor is given by $\boldsymbol{\sigma}^{\mathrm{s}}(\boldsymbol{d}, \dot{\boldsymbol{d}}) \stackrel{\text { def }}{=} \boldsymbol{\sigma}(\boldsymbol{d})+\beta \boldsymbol{\sigma}(\dot{\boldsymbol{d}})$, with $\boldsymbol{\sigma}(\boldsymbol{d}) \stackrel{\text { def }}{=} 2 L_{1} \boldsymbol{\epsilon}(\boldsymbol{d})+\left(L_{2} \operatorname{div} \boldsymbol{d}\right) \boldsymbol{I}$ and $L_{1}, L_{2}>0$ the Lamé constants. The presence of dissipative effects in the structure is described by the term $c_{1} \dot{\boldsymbol{d}}-\beta \boldsymbol{d i v} \boldsymbol{\sigma}(\dot{\boldsymbol{d}})$, the so-called Rayleigh damping (see, e.g., [5]), with $c_{1} \stackrel{\text { def }}{=} \alpha\left(1+\beta c_{0}\right)$ and $c_{0}, \alpha, \beta \geq$ 0 . The zeroth-order term, $c_{0} \boldsymbol{d}$, allows to incorporate the transversal membrane effects that appear in axisymmetric formulations. In what follows, we shall make use of the functional spaces $\boldsymbol{V}^{\mathrm{f}} \stackrel{\text { def }}{=}\left[H^{1}\left(\Omega^{\mathrm{f}}\right)\right]^{d}$, $Q \stackrel{\text { def }}{=} L^{2}\left(\Omega^{\mathrm{f}}\right), \boldsymbol{V}^{\mathrm{s}} \stackrel{\text { def }}{=}\left\{\boldsymbol{v}^{\mathrm{s}} \in\left[H^{1}\left(\Omega^{\mathrm{s}}\right)\right]^{d},\left.\boldsymbol{v}^{\mathrm{s}}\right|_{\Gamma^{\mathrm{d}}}=0\right\}$ and $\widetilde{\boldsymbol{V}}^{\mathrm{s}} \stackrel{\text { def }}{=}\left\{\boldsymbol{v}^{\mathrm{s}} \in\left[H^{1}\left(\Omega^{\mathrm{s}}\right)\right]^{d},\left.\boldsymbol{v}^{\mathrm{s}}\right|_{\Gamma^{\mathrm{d}} \cup \Sigma}=0\right\}$. We also set

$$
\begin{aligned}
& a\left(\boldsymbol{u}, \boldsymbol{v}^{\mathrm{f}}\right) \stackrel{\text { def }}{=} 2 \mu\left(\boldsymbol{\epsilon}(\boldsymbol{u}), \boldsymbol{\epsilon}\left(\boldsymbol{v}^{\mathrm{f}}\right)\right)_{\Omega^{\mathrm{f}}}, \quad b\left(p, \boldsymbol{v}^{\mathrm{f}}\right) \stackrel{\text { def }}{=}-\left(p, \operatorname{div} \boldsymbol{v}^{\mathrm{f}}\right)_{\Omega^{\mathrm{f}}}, \quad\left\langle p_{\Gamma}, \boldsymbol{v}^{\mathrm{f}}\right\rangle \stackrel{\text { def }}{=}-\left(p_{\Gamma}, \boldsymbol{v}^{\mathrm{f}} \cdot \boldsymbol{n}^{\mathrm{f}}\right)_{\Gamma}, \\
& a_{\mathrm{e}}\left(\boldsymbol{d}, \boldsymbol{v}^{\mathrm{s}}\right) \stackrel{\text { def }}{=}\left(\boldsymbol{\sigma}(\boldsymbol{d}), \boldsymbol{\epsilon}\left(\boldsymbol{v}^{\mathrm{s}}\right)\right)_{\Omega^{\mathrm{s}}}+c_{0}\left(\boldsymbol{d}, \boldsymbol{v}^{\mathrm{s}}\right)_{\Omega^{\mathrm{s}}}, \quad a_{\mathrm{v}}\left(\dot{\boldsymbol{d}}, \boldsymbol{v}^{\mathrm{s}}\right) \stackrel{\text { def }}{=} \beta a_{\mathrm{e}}\left(\dot{\boldsymbol{d}}, \boldsymbol{v}^{\mathrm{s}}\right)+\alpha\left(\dot{\boldsymbol{d}}, \boldsymbol{v}^{\mathrm{s}}\right)_{\Omega^{\mathrm{s}}} .
\end{aligned}
$$

The symbol $(\cdot, \cdot)_{\omega}$ denotes de inner-product of $L^{2}(\omega)$ and $\|\cdot\|_{0, \omega}$ its associated norm. Problem (1)-(2) can then be rewritten in variational form as follows: For $t>0$, find the fluid velocity and pressure $(\boldsymbol{u}(t), p(t)) \in \boldsymbol{V}^{\mathrm{f}} \times L^{2}(\Omega)$ and the solid displacement and velocity $\boldsymbol{d}(t), \dot{\boldsymbol{d}}(t) \in \boldsymbol{V}^{\mathrm{s}}$, such that $\dot{\boldsymbol{d}}=\partial_{t} \boldsymbol{d}$ and

$$
\left\{\begin{array}{l}
\left.\boldsymbol{u}\right|_{\Sigma}=\left.\dot{\boldsymbol{d}}\right|_{\Sigma}, \\
\rho^{\mathrm{f}}\left(\partial_{t} \boldsymbol{u}, \boldsymbol{v}^{\mathrm{f}}\right)_{\Omega^{\mathrm{f}}}+a\left(\boldsymbol{u}, \boldsymbol{v}^{\mathrm{f}}\right)+b\left(p, \boldsymbol{v}^{\mathrm{f}}\right)-b(q, \boldsymbol{u})+\rho^{\mathrm{s}}\left(\partial_{t} \dot{\boldsymbol{d}}, \boldsymbol{v}^{\mathrm{s}}\right)_{\Omega^{\mathrm{s}}}+a_{\mathrm{v}}\left(\dot{\boldsymbol{d}}, \boldsymbol{v}^{\mathrm{s}}\right)+a_{\mathrm{e}}\left(\boldsymbol{d}, \boldsymbol{v}^{\mathrm{s}}\right)=\left\langle p_{\Gamma}, \boldsymbol{v}^{\mathrm{f}}\right\rangle
\end{array}\right.
$$

for all $\left(\boldsymbol{v}^{\mathrm{f}}, q, \boldsymbol{v}^{\mathrm{s}}\right) \in \boldsymbol{V}^{\mathrm{f}} \times Q \times \boldsymbol{V}^{\mathrm{s}}$ with $\left.\boldsymbol{v}^{\mathrm{f}}\right|_{\Sigma}=\left.\boldsymbol{v}^{\mathrm{s}}\right|_{\Sigma}$.

\section{Displacement-velocity correction explicit coupling schemes}

In this section, we address the time and space discretization of the coupled problem (3). The space discretization is based on continuous piecewise-affine approximations, with a lumped-mass approximation in the structure. We denote by $\boldsymbol{V}_{h}^{\mathrm{f}} \subset \boldsymbol{V}^{\mathrm{f}}, Q_{h} \subset Q, \boldsymbol{V}_{h}^{\mathrm{s}} \subset \boldsymbol{V}^{\mathrm{s}}$ and $\widetilde{\boldsymbol{V}}_{h}^{\mathrm{s}} \stackrel{\text { def }}{=} \boldsymbol{V}_{h}^{\mathrm{s}} \cap \widetilde{\boldsymbol{V}}^{\mathrm{s}}$ the corresponding 
finite element spaces, and the bi-linear form $s_{h}(\cdot, \cdot)$ stands for a given symmetric pressure stabilization operator (see, e.g., [6]). We assume that the fluid and solid discretizations match at the interface, viz., $\boldsymbol{X}_{\Sigma, h} \stackrel{\text { def }}{=}\left\{\left.\boldsymbol{v}_{h}^{\mathrm{f}}\right|_{\Sigma}, \boldsymbol{v}_{h}^{\mathrm{f}} \in \boldsymbol{V}_{h}^{\mathrm{f}}\right\}=\left\{\left.\boldsymbol{v}_{h}^{\mathrm{s}}\right|_{\Sigma}, \boldsymbol{v}_{h}^{\mathrm{s}} \in \boldsymbol{V}_{h}^{\mathrm{s}}\right\}$. In what follows, we shall make use of the standard (solid-sided) lifting operator $\mathcal{L}_{h}: \boldsymbol{X}_{\Sigma, h} \rightarrow \boldsymbol{V}_{h}^{\mathrm{s}}$ defined in such a way that $\left.\mathcal{L}_{h} \boldsymbol{\xi}_{h}\right|_{\Sigma}=\boldsymbol{\xi}_{h}$ and that the nodal values of $\mathcal{L}_{h} \boldsymbol{\xi}_{h}$ vanish out of $\Sigma$. Note that, for all $\boldsymbol{v}_{h}^{\mathrm{s}} \in \boldsymbol{V}_{h}^{\mathrm{s}}$, we have the decomposition $\boldsymbol{v}_{h}^{\mathrm{s}}=$ $\mathcal{L}_{h} \boldsymbol{v}_{h}^{\mathrm{s}}+\widetilde{\boldsymbol{v}}_{h}^{\mathrm{s}}$, with $\widetilde{\boldsymbol{v}}_{h}^{\mathrm{s}} \stackrel{\text { def }}{=} \boldsymbol{v}_{h}^{\mathrm{s}}-\mathcal{L}_{h} \boldsymbol{v}_{h}^{\mathrm{s}} \in \widetilde{\boldsymbol{V}}_{h}^{\mathrm{s}}$. We denote by $(\cdot, \cdot)_{\mathrm{s}, h}$ the lumped-mass approximation of the inner-product $(\cdot, \cdot)_{\Omega^{\mathrm{s}}}$ (see, e.g., [7]), and we set $a_{\mathrm{v}, h}(\cdot, \cdot) \stackrel{\text { def }}{=} \beta a_{\mathrm{e}}(\cdot, \cdot)+\alpha(\cdot, \cdot)_{\mathrm{s}, h}$. At last, we introduce the following discrete Ritz-representation operators with respect to the inner-product $(\cdot, \cdot)_{\mathrm{s}, h}$ : For each $\boldsymbol{v}^{\mathrm{s}} \in$ $\boldsymbol{V}^{\mathrm{s}}$, we define $\boldsymbol{L}_{h}^{\mathrm{e}} \boldsymbol{v}^{\mathrm{s}}, \boldsymbol{L}_{h}^{\mathrm{v}} \boldsymbol{v}^{\mathrm{s}} \in \boldsymbol{V}_{h}^{\mathrm{s}}$ such that $\left(\boldsymbol{L}_{h}^{\mathrm{e}} \boldsymbol{v}^{\mathrm{s}}, \boldsymbol{v}_{h}^{\mathrm{s}}\right)_{\mathrm{s}, h}=a_{\mathrm{e}}\left(\boldsymbol{v}^{\mathrm{s}}, \boldsymbol{v}_{h}^{\mathrm{s}}\right)$ and $\left(\boldsymbol{L}_{h}^{\mathrm{v}} \boldsymbol{v}^{\mathrm{s}}, \boldsymbol{v}_{h}^{\mathrm{s}}\right)_{\mathrm{s}, h}=a_{\mathrm{v}, h}\left(\boldsymbol{v}^{\mathrm{s}}, \boldsymbol{v}_{h}^{\mathrm{s}}\right)$ for all $\boldsymbol{v}_{h}^{\mathrm{s}} \in \boldsymbol{V}_{h}^{\mathrm{s}}$. The discretization in time is performed with a displacement-velocity correction coupling scheme. Hence, the time-marching of (3) is split into three sequential sub-steps: the solid displacement and velocity are treated explicitly (or ignored) in the first two steps and then corrected in the third. The proposed fully discrete schemes are detailed in Algorithm 1, where $\tau>0$ denotes the time-step size, $t_{n} \stackrel{\text { def }}{=} n \tau, \partial_{\tau} x^{n} \stackrel{\text { def }}{=}\left(x^{n}-x^{n-1}\right) / \tau$ and $\left(\boldsymbol{d}_{h}^{\star}, \dot{\boldsymbol{d}}_{h}^{\star}\right)=(\mathbf{0}, \mathbf{0}),\left(\boldsymbol{d}_{h}^{n-1}, \dot{\boldsymbol{d}}_{h}^{n-1}\right),\left(2 \boldsymbol{d}_{h}^{n-1}-\boldsymbol{d}_{h}^{n-2}, 2 \dot{\boldsymbol{d}}_{h}^{n-1}-\dot{\boldsymbol{d}}_{h}^{n-2}\right)$ are the, zeroth-, first- and second-order extrapolations, respectively.

Algorithm 1 Displacement-velocity correction explicit coupling schemes.

(i) Robin-like fluid step: Find $\left(\boldsymbol{u}_{h}^{n}, p_{h}^{n}\right) \in \boldsymbol{V}_{h}^{\mathrm{f}} \times Q_{h}$ such that

$$
\begin{aligned}
& \rho^{\mathrm{f}}\left(\partial_{\tau} \boldsymbol{u}_{h}^{n}, \boldsymbol{v}_{h}^{\mathrm{f}}\right)_{\Omega^{\mathrm{f}}}+a\left(\boldsymbol{u}_{h}^{n}, \boldsymbol{v}_{h}^{\mathrm{f}}\right)+b\left(p_{h}^{n}, \boldsymbol{v}_{h}^{\mathrm{f}}\right)-b\left(q_{h}, \boldsymbol{u}_{h}^{n}\right)+s_{h}\left(p_{h}^{n}, q_{h}\right) \\
& +\frac{\rho^{\mathrm{s}}}{\tau}\left(\mathcal{L}_{h} \boldsymbol{u}_{h}^{n}, \mathcal{L}_{h} \boldsymbol{v}_{h}^{\mathrm{f}}\right)_{\mathrm{s}, h}=\left\langle p_{\Gamma}\left(t_{n}\right), \boldsymbol{v}_{h}^{\mathrm{f}}\right\rangle+\frac{\rho^{\mathrm{s}}}{\tau}\left(\dot{\boldsymbol{d}}_{h}^{n-1}, \mathcal{L}_{h} \boldsymbol{v}_{h}^{\mathrm{f}}\right)_{\mathrm{s}, h}-a_{\mathrm{e}}\left(\boldsymbol{d}_{h}^{\star}, \mathcal{L}_{h} \boldsymbol{v}_{h}^{\mathrm{f}}\right)-a_{\mathrm{v}, h}\left(\dot{\boldsymbol{d}}_{h}^{\star}, \mathcal{L}_{h} \boldsymbol{v}_{h}^{\mathrm{f}}\right)
\end{aligned}
$$

for all $\left(\boldsymbol{v}_{h}^{\mathrm{f}}, q_{h}\right) \in \boldsymbol{V}_{h}^{\mathrm{f}} \times Q_{h}$.

(ii) Intermediate solid velocity: Find $\widetilde{\boldsymbol{w}}_{h}^{n} \in \widetilde{\boldsymbol{V}}_{h}^{\mathrm{s}}$ such that

$$
\frac{\rho^{\mathbf{s}}}{\tau}\left(\widetilde{\boldsymbol{w}}_{h}^{n}, \widetilde{\boldsymbol{v}}_{h}^{\mathrm{s}}\right)_{\mathrm{s}, h}=\frac{\rho^{\mathrm{s}}}{\tau}\left(\dot{\boldsymbol{d}}_{h}^{n-1}, \widetilde{\boldsymbol{v}}_{h}^{\mathrm{s}}\right)_{\mathrm{s}, h}-a_{\mathrm{e}}\left(\boldsymbol{d}_{h}^{\star}, \widetilde{\boldsymbol{v}}_{h}^{\mathrm{s}}\right)-a_{\mathrm{v}, h}\left(\dot{\boldsymbol{d}}_{h}^{\star}, \widetilde{\boldsymbol{v}}_{h}^{\mathrm{s}}\right)
$$

for all $\widetilde{\boldsymbol{v}}_{h}^{\mathrm{s}} \in \widetilde{\boldsymbol{V}}_{h}^{\mathrm{s}}$. Then set $\boldsymbol{w}_{h}^{n} \stackrel{\text { def }}{=} \mathcal{L}_{h} \boldsymbol{u}_{h}^{n}+\widetilde{\boldsymbol{w}}_{h}^{n} \in \boldsymbol{V}_{h}^{\mathrm{s}}$.

(iii) Solid displacement-velocity correction: Find $\boldsymbol{d}_{h}^{n} \in \boldsymbol{V}_{h}^{\mathrm{s}}$ such that $\dot{\boldsymbol{d}}_{h}^{n}=\partial_{\tau} \boldsymbol{d}_{h}^{n}$ and

$$
\frac{\rho^{\mathrm{s}}}{\tau}\left(\dot{\boldsymbol{d}}_{h}^{n}, \boldsymbol{v}_{h}^{\mathrm{s}}\right)_{\mathrm{s}, h}+a_{\mathrm{e}}\left(\boldsymbol{d}_{h}^{n}, \boldsymbol{v}_{h}^{\mathrm{s}}\right)+a_{\mathrm{v}, h}\left(\dot{\boldsymbol{d}}_{h}^{n}, \boldsymbol{v}_{h}^{\mathrm{s}}\right)=\frac{\rho^{\mathrm{s}}}{\tau}\left(\boldsymbol{w}_{h}^{n}, \boldsymbol{v}_{h}^{\mathrm{s}}\right)_{\mathrm{s}, h}+a_{\mathrm{e}}\left(\boldsymbol{d}_{h}^{\star}, \boldsymbol{v}_{h}^{\mathrm{s}}\right)+a_{\mathrm{v}, h}\left(\dot{\boldsymbol{d}}_{h}^{\star}, \boldsymbol{v}_{h}^{\mathrm{s}}\right)
$$

for all $\boldsymbol{v}_{h}^{\mathrm{s}} \in \boldsymbol{V}_{h}^{\mathrm{s}}$.

Algorithm 1 generalizes the explicit coupling schemes reported in $[3,4]$ to the case of thick structures. The structural damping $a_{\mathrm{v}, h}(\cdot, \cdot)$ is explicitly coupled to the fluid. This allows to uncouple the computation of the interface and internal components $\left(\mathcal{L}_{h} \boldsymbol{u}_{h}^{n}\right.$ and $\left.\widetilde{\boldsymbol{w}}_{h}^{n}\right)$ of the intermediate solid velocity $\boldsymbol{w}_{h}^{n}$, via a masslumping approximation in the structure. The fluid step (i) has a Robin-like structure, due to the presence of the term $\rho^{\mathrm{s}} / \tau\left(\mathcal{L}_{h} \boldsymbol{u}_{h}^{n}, \mathcal{L}_{h} \boldsymbol{v}_{h}^{\mathrm{f}}\right)_{\mathrm{s}, h}$ (interface lumped-mass contribution of the structure). Step (ii), which only involves the resolution of a diagonal system (internal lumped-mass contribution), is not present in the case of thin structures (see [3,4]). Observe that the addition of (4), (5) and (6) yields

$$
\begin{aligned}
\rho^{\mathrm{f}}\left(\partial_{\tau} \boldsymbol{u}_{h}^{n}, \boldsymbol{v}_{h}^{\mathrm{f}}\right)_{\Omega^{\mathrm{f}}}+a\left(\boldsymbol{u}_{h}^{n}, \boldsymbol{v}_{h}^{\mathrm{f}}\right)+b\left(p_{h}^{n}, \boldsymbol{v}_{h}^{\mathrm{f}}\right)-b\left(q_{h}, \boldsymbol{u}_{h}^{n}\right)+s_{h}\left(p_{h}^{n}, q_{h}\right) \\
+\rho^{\mathrm{s}}\left(\partial_{\tau} \dot{\boldsymbol{d}}_{h}^{n}, \boldsymbol{v}_{h}^{\mathrm{s}}\right)_{\mathrm{s}, h}+a_{\mathrm{e}}\left(\boldsymbol{d}_{h}^{n}, \boldsymbol{v}_{h}^{\mathrm{s}}\right)+a_{\mathrm{v}, h}\left(\dot{\boldsymbol{d}}_{h}^{n}, \boldsymbol{v}_{h}^{\mathrm{s}}\right)=\left\langle p_{\Gamma}\left(t_{n}\right), \boldsymbol{v}_{h}^{\mathrm{f}}\right\rangle
\end{aligned}
$$

for all $\left(\boldsymbol{v}_{h}^{\mathrm{f}}, q_{h}, \boldsymbol{v}_{h}^{\mathrm{s}}\right) \in \boldsymbol{V}_{h}^{\mathrm{f}} \times Q_{h} \times \boldsymbol{V}_{h}^{\mathrm{s}}$ such that $\left.\boldsymbol{v}_{h}^{\mathrm{f}}\right|_{\Sigma}=\left.\boldsymbol{v}_{h}^{\mathrm{s}}\right|_{\Sigma}$. On the other hand, from (6) and (ii) we get 


$$
\boldsymbol{u}_{h}^{n}=\dot{\boldsymbol{d}}_{h}^{n}+\frac{\tau}{\rho^{\mathrm{s}}} \boldsymbol{L}_{h}^{\mathrm{e}}\left(\boldsymbol{d}_{h}^{n}-\boldsymbol{d}_{h}^{\star}\right)+\frac{\tau}{\rho^{\mathrm{s}}} \boldsymbol{L}_{h}^{\mathrm{v}}\left(\dot{\boldsymbol{d}}_{h}^{n}-\dot{\boldsymbol{d}}_{h}^{\star}\right) \quad \text { on } \quad \Sigma .
$$

Therefore (as in the case of thin-solid models [4]), the explicit coupling schemes reported in Algorithm 1 can be interpreted as implicit time discretizations of $(3)_{2}$ (given by $(7)$ ) that involve a weakly consistent correction of the kinematic constraint $(3)_{1}$ (given by $(8)$ ).

\section{Stability}

We define the discrete energy and dissipation of the fluid-structure system, at time $t_{n}$, as

$$
E_{h}^{n} \stackrel{\text { def }}{=} \frac{\rho^{\mathrm{f}}}{2}\left\|\boldsymbol{u}_{h}^{n}\right\|_{0, \Omega^{\mathrm{f}}}^{2}+\frac{\rho^{\mathrm{s}}}{2}\left\|\dot{\boldsymbol{d}}_{h}^{n}\right\|_{0, \Omega^{\mathrm{s}}}^{2}+\frac{1}{2} a_{\mathrm{e}}\left(\boldsymbol{d}_{h}^{n}, \boldsymbol{d}_{h}^{n}\right), \quad D_{h}^{n} \stackrel{\text { def }}{=} \tau \sum_{m=1}^{n}\left(2 \mu\left\|\boldsymbol{\epsilon}\left(\boldsymbol{u}_{h}^{m}\right)\right\|_{0, \Omega^{\mathrm{f}}}^{2}+a_{\mathrm{v}}\left(\dot{\boldsymbol{d}}_{h}^{m}, \dot{\boldsymbol{d}}_{h}^{m}\right)\right) .
$$

We have the following stability result, whose proof can be found in [8]. The symbol $\lesssim$ indicates an inequality up to a multiplicative constant (independent of the physical and discretization parameters).

Proposition 4.1 Assume that $p_{\Gamma}=0$ (free system).

- Non-incremental scheme (zeroth-order extrapolation): For $n \geq 1$, there holds

$$
E_{h}^{n}+D_{h}^{n} \lesssim E_{h}^{0}
$$

- Incremental scheme, first-order extrapolation: For $n \geq 1$, there holds

$$
E_{h}^{n}+D_{h}^{n} \lesssim E_{h}^{0}+\tau^{2} a_{\mathrm{e}}\left(\dot{\boldsymbol{d}}_{h}^{0}, \dot{\boldsymbol{d}}_{h}^{0}\right)+\frac{\tau^{2}}{\rho^{\mathrm{s}}}\left\|\boldsymbol{L}_{h}^{\mathrm{e}} \boldsymbol{d}_{h}^{0}+\boldsymbol{L}_{h}^{\mathrm{v}} \dot{\boldsymbol{d}}_{h}^{0}\right\|_{0, \Omega^{\mathrm{s}}}^{2}
$$

- Incremental scheme, second-order extrapolation: Under the conditions

$$
\beta \rho^{\mathrm{s}} \omega_{\mathrm{e}}^{2} \tau+\alpha \tau h^{2}<\rho^{\mathrm{s}} h^{2}, \quad \tau \omega_{\mathrm{e}}^{\frac{6}{5}} \leq c_{\mathrm{e}} h^{\frac{6}{5}}, \quad \beta \rho^{\mathrm{s}} \omega_{\mathrm{e}}^{2} \tau^{2}+\alpha \omega_{\mathrm{e}}^{2} \tau h^{4} \leq c_{\mathrm{v}}^{2} \rho^{\mathrm{s}} h^{4}, \quad \tau\left(c_{\mathrm{e}}^{5}+c_{\mathrm{v}}^{2}\right)<1,
$$

there holds, for $n \geq 2$,

$$
E_{h}^{n}+D_{h}^{n} \lesssim e^{t_{n} /\left(\left(c_{\mathrm{e}}^{5}+c_{\mathrm{v}}^{2}\right)^{-1}-\tau\right)}\left(E_{h}^{1}+a_{\mathrm{v}}\left(\dot{\boldsymbol{d}}_{h}^{1}-\dot{\boldsymbol{d}}_{h}^{0}, \dot{\boldsymbol{d}}_{h}^{1}-\dot{\boldsymbol{d}}_{h}^{0}\right)\right)
$$

where $\omega_{\mathrm{e}}$ represents a maximum elastic-wave speed in the solid.

Some remarks are in order. The above result shows that the non-incremental and the first-order extrapolated incremental schemes are unconditionally stable in the energy norm (the latter under additional regularity on the initial data). Proposition 4.1 also shows that, with second-order extrapolation, the incremental variant is conditionally energy stable. For undamped solids (i.e., $\alpha=\beta=0$ ), the stability condition (9) becomes a 6/5-CFL constraint and the estimates of Proposition 4.1 are similar to those obtained in [4] with a thin-solid model. For $\beta>0$, the condition (9) involves a parabolic-CFL constraint. Note that the estimate (10) involves a constant growing exponentially in time (from Gronwall's lemma).

\section{Numerical experiments}

In order to illustrate the accuracy of the proposed schemes, we have performed a series of numerical tests in a two-dimensional pressure-wave propagation benchmark (see [9], for instance). The fluid and solid domains are given, respectively, by the rectangles $\Omega^{\mathrm{f}}=[0,6] \times[0,0.5]$ and $\Omega^{\mathrm{s}}=[0,6] \times[0.5,0.6]$. The interface is $\Sigma=[0,6] \times\{0.5\}$ and we have $\Gamma^{\mathrm{d}}=\{0,6\} \times[0.5,0.6]$ and $\Gamma^{\mathrm{n}}=[0,6] \times\{0.6\}$. All units are in the CGS system. At $x=0$, a sinusoidal pressure of maximal amplitude $2 \times 10^{4}$ is imposed during $5 \times 10^{-3} \mathrm{~s}$, corresponding to half a period. Zero pressure is enforced at $x=6$ and a symmetry condition is applied 
on the lower wall $y=0$. The fluid physical parameters are given by $\rho^{\mathrm{f}}=1.0 \mathrm{~g} . \mathrm{cm}^{-3}, \mu=0.035 \mathrm{P}$. For the solid we have $\rho^{\mathrm{s}}=1.1 \mathrm{~g} . \mathrm{cm}^{-3}, L_{1}=1.15 \times 10^{6}$ dyn. $\mathrm{cm}^{-2}, L_{2}=1.7 \times 10^{6}$ dyn.cm ${ }^{-2}, c_{0}=4 \times 10^{6}$ dyn.cm ${ }^{-4}$, $\alpha=\beta=0$ (i.e., undamped solid, for a numerical study with structural damping we refer to [8]). The computations have been performed with FreeFem $++[10]$. Figure 1 reports the time-convergence history
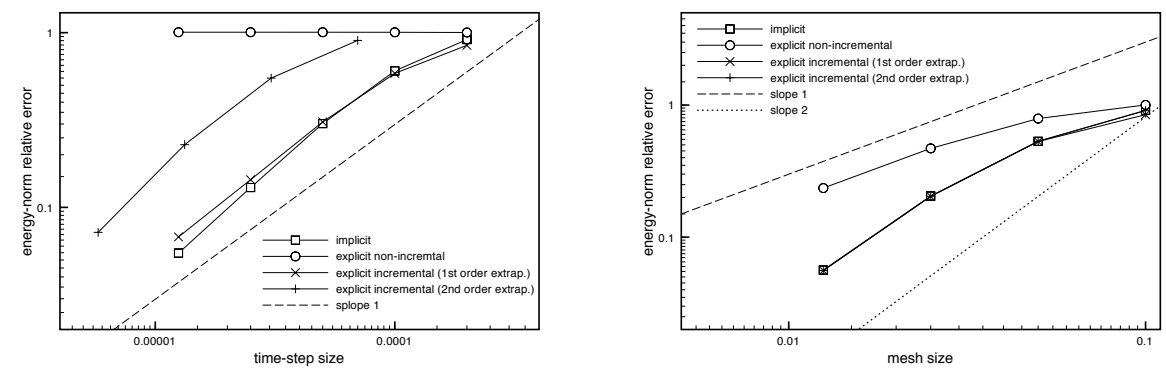

Figure 1. Solid displacement convergence history. Left: $\tau=\mathcal{O}(h)\left(\tau=\mathcal{O}\left(h^{6 / 5}\right)\right.$ with second-order extrap.). Right: $\tau=\mathcal{O}\left(h^{2}\right)$.

of the solid displacement, in the relative energy-norm at time $t=1.5 \times 10^{-2}$, for the incremental, nonincremental and implicit schemes. The reference solution has been generated with the implicit scheme and a high grid resolution: $\tau=2.5 \times 10^{-7}$ and $h=3.125 \times 10^{-3}$. We have refined both in time and in space. Figure 1(left) shows that, in the case $\tau=\mathcal{O}(h)\left(\tau=\mathcal{O}\left(h^{6 / 5}\right)\right.$ with second-order extrap.), the incremental and implicit schemes yield an overall $\mathcal{O}(\tau)$ optimal accuracy. Note that the second-order extrapolation does not improve the convergence rate, since the overall time-accuracy of the underlying implicit scheme in Algorithm 1 is $\mathcal{O}(\tau)$. On the contrary, the non-incremental variant is unable to show a convergent behavior towards the reference solution (saturation of the error). Yet, Figure 1(right) shows that this scheme achieves an overall $O(h)$ accuracy under a parabolic $\tau=\mathcal{O}\left(h^{2}\right)$ time-step restriction. This suggests that the non-incremental scheme introduces a sub-optimal $\mathcal{O}\left(\tau^{\frac{1}{2}}\right)$ perturbation in the error. The superior accuracy of the incremental variants is also highlighted by Figure 1(right).

\section{References}

[1] M. Fernández, J.-F. Gerbeau, Algorithms for fluid-structure interaction problems, in: Cardiovascular mathematics, Vol. 1 of MS\&A. Model. Simul. Appl., Springer, 2009, pp. 307-346.

[2] E. Burman, M. Fernández, Stabilization of explicit coupling in fluid-structure interaction involving fluid incompressibility, Comput. Methods Appl. Mech. Engrg. 198 (5-8) (2009) 766-784.

[3] G. Guidoboni, R. Glowinski, N. Cavallini, S. Canic, Stable loosely-coupled-type algorithm for fluid-structure interaction in blood flow, J. Comp. Phys. 228 (18) (2009) 6916-6937.

[4] M. Fernández, Incremental displacement-correction schemes for the explicit coupling of a thin structure with an incompressible fluid, C. R. Math. Acad. Sci. Paris 349 (7-8) (2011) 473-477.

[5] T. Hughes, The finite element method, Prentice Hall, 1987.

[6] E. Burman, M. Fernández, Galerkin finite element methods with symmetric pressure stabilization for the transient Stokes equations: stability and convergence analysis, SIAM J. Numer. Anal. 47 (1) (2008/09) 409-439.

[7] V. Thomée, Galerkin finite element methods for parabolic problems, Springer, 2006.

[8] M. Fernández, J. Mullaert, Diplacement-velocity correction schemes for incompressible fluid-structure interaction: Stability analysis and numerics, in preparation.

[9] S. Badia, F. Nobile, C. Vergara, Fluid-structure partitioned procedures based on Robin transmission conditions, J. Comp. Phys. 227 (2008) 7027-7051.

[10] O. Pironneau, F. Hecht, A. Le Hyaric, J. Morice, Freefem++, www.freefem.org/ff++. 